\title{
Trace Elements and Electrolytes Homeostasis and Their Relation to Antioxidant Enzyme Activity in Brain Hyperexcitability of Epileptic Patients
}

\author{
Sherifa A. Hamed ${ }^{1, *}$ and Moustafa M. Abdellah ${ }^{2}$ \\ Departments of ${ }^{1}$ Neurology and ${ }^{2}$ Pharmacology, Assiut University Hospital, Assiut, Egypt
}

Received September 27, 2004

\begin{abstract}
Epileptogenesis is a big challenge. Various experimental and human studies suggested that the homeostasis of trace elements, electrolytes, membrane lipid peroxidation, and antioxidants is crucial for brain function, and they were directly or indirectly implicated as taking part in the pathophysiology of neuronal excitability, neuronal excitotoxicity, and seizure recurrence and its resistance to treatment with antiepileptic drugs (AEDs). In addition, AEDs can also alter the homeostasis of trace elements, electrolytes, and seriously increase membrane lipid peroxidation at the expense of protective antioxidants, leading to an increase in seizure recurrence and an idiosyncratic drug effect. Differential effects were detected among different AEDs treatments in which carbamazepine (CBZ) was found to be better anticonvulsant for the control of free radical related seizures and the level of trace elements were better regulated with CBZ than with valproate (VPA) and phenytoin (PHT) therapies. It is concluded that adequate trace elements and antioxidants supply is important for brain functions and prevention of neurological diseases and further elucidation of the pathological actions of such substances in the brain should result in new therapeutic approaches. Trace elements and antioxidant might have neuroprotective biological targeted benefits when used in epileptic patients.
\end{abstract}

Keywords: trace element, lipid peroxidation, antioxidant, neuronal excitotoxicity, antiepileptic drug

\section{Introduction}

Trace elements (e.g., zinc, selenium, and copper) are minor building components in tissues including the nervous system. The very complex balance of trace elements is crucial for all areas of maintaining human health, preventing as well as overcoming health problems (1). The brain barrier system, that is, the blood-brain and blood cerebrospinal fluid (CSF) barriers, is important for trace element homeostasis in the brain (2). The concentration of trace elements in cerebral tissue is not equal in all parts of the brain (3).

Trace elements play important functional roles in peripheral and central nervous systems $(4-9)$. Zinc,

*Corresponding author. FAX: +20-882333327

E-mail: Shamed50@hotmail.com

Invited article selenium, and copper are indispensable components for certain enzymes responsible for various metabolic processes in different tissues including the brain (10, 11). They are important parts of antioxidant enzymes such as superoxide dismutase (SOD), glutathione peroxidase (GSH-Px) as well as transport protein with antioxidant properties, ceruloplasmin ( $\mathrm{Crl}$ ) (a copperbinding protein), providing protection against peroxidative superoxide radicals damage. Through enzymatic or indirect action, they block destructive alteration of lipids, proteins, and nucleic acids by oxygen-derived free radicals, radiation, certain heavy metals, and other toxic substances (12). Vitamin E and GSH-Px have similar and complementary physiological roles in protecting cells from damage caused by endogenous peroxides (13). Furthermore, trace elements are also important for the development of the nervous system, myelination of nerve fibers $(11,14)$, and neuronal excitability (8). 
Many previous studies demonstrated that the abnormal metabolism of trace elements, electrolytes, and antioxidants might be involved in the pathophysiology of severe mental and neurological disorders including epilepsy $(2,15,16)$.

\section{The pathophysiological mechanisms yielding epilepto- genetic and neuronal excitotoxic effect of trace elements, membrane lipid peroxidation, and anti- oxidant system}

Epilepsy is a big challenge for scientists and many workers have been exploring different aspects of this disease. The mechanisms of epileptogenesis are not well established. Research employing experimental models of epilepsy suggested that alteration of homeostasis of some trace elements in the brain may be involved in the susceptibility, development, and termination of seizures in animal models of genetically determined epilepsy (17). Theoretically, trace elements may play a role in the production of seizures and their control in humans. This concept has led to several studies. However, the relation between epilepsy and trace elements has never been convincingly documented in human studies because the data in the literature are conflicting and this association is poorly understood $(18-20)$. Many studies suggested that the body electrolytes, the level of some trace elements, and the membrane lipid peroxidation due to increase in free radicals or decrease in activities of antioxidant defense mechanisms have been causally involved in some forms of epilepsies and seizure recurrence $(21-23)$. Moreover, some antiepileptic drugs (AEDs) may alter trace element metabolism and free radical scavenging enzyme activities in humans and experimental animals $(7,10,24-30)$.

\section{Zinc}

In the brain, Zinc $\left(\mathrm{Zn}^{2+}\right)$ is abundant, having, after iron, the highest concentrations among all transition metals. Most of this brain zinc (approximately 90\%) is bound up in metal-protein complexes. Many neurons in addition contain a significant amount of reactive ionic zinc. Within the telencephalon, zinc-containing fiber systems form vast association networks that reciprocally interconnects isocortical, allocortical, and limbic structures. Large amounts of chelatable $\mathrm{Zn}^{2+}$ are concentrated also in the limbic region, notably in the hippocampus formation (31). Approximately $10 \%$ of the total $\mathrm{Zn}^{2+}$ in the brain, probably ionic $\mathrm{Zn}^{2+}$, exist in the synaptic vesicles of what is known as zinc-containing neurons (a subclass of a glutaminergic neurons) and is released in a calcium and impulse-dependent manner (9). Because the hippocampal, amygdalar, and perirhinal regions are prominent nodes in this glutaminergic network, it is presumed that vesicular $\mathrm{Zn}^{2+}$ is involved in modulation of neuronal excitability and in the synaptic plasticity of developmental and experiential learning (9). $\mathrm{Zn}^{2+}$ is a potent modulator of amino acid receptors (especially the NMDA receptor) and co-release of zinc along with glutamate would provide a mechanism for modulating postsynaptic excitability with little or no effect at physiological firing rates, but selectively depressing excitability (by NMDA-receptor depression) when firing rates reach dangerous, paroxysmal levels (9). The precise mechanism by which zinc interferes with NMDA function is unknown, but appears to act as a non-competitive antagonist whose major site of action is outside the channel pore in contrast to the action of divalent cations, notably magnesium $\left(\mathrm{Mg}^{2+}\right)$, which binds within the pore to block ion permeation (32). In addition, glutaminergic synapses may have differential sensitivities to zinc inhibition and might even be capable of modulating their sensitivity by altering NMDA subunit composition (33). It has been reported that vesicular zinc enriched regions, for example, the hippocampus, are responsive to dietary zinc deprivation, which also causes brain dysfunction such as learning impairment and olfactory dysfunction (2).

Pathophysiologic mechanisms yielding epileptogenetic effect of zinc: Altered zinc metabolism may play a role in the development of epilepsy. Zinc homeostasis in the brain is closely related to neuronal activity. It has been reported that susceptibility to epileptic seizures, which may decrease vesicular zinc, is also enhanced by zinc deficiency $(2,34)$. Experimental studies revealed that the concentration of zinc was decreased in the piriform cortex and amygdaloid nuclei complex during convulsions. The decrease in activity functioning zinc in the brain may be associated with the increase in the susceptibility to seizures in El mouse (a genetically animal model of epilepsy) (34). In contrast, zinc ions were found to inhibit the activity of $\mathrm{Na}^{+}-\mathrm{K}^{+}$ATPase enzyme, which is known to concentrate in the hippocampus $(4,35)$. It was claimed that this situation increased the neuronal excitability and led to seizure (10). In addition, $\mathrm{Zn}^{2+}$ can inhibit glutamic acid decarboxylaase activity, thereby resulting in decreased levels of GABA or an increase in carbonic anhydrase activity (36). Several lines of evidence point to the possible role of zinc in the pathological changes occuring in the hippocampus in temporal lobe epilepsy, death of hippocampal neurons, and aberrant sprouting of hippocampal mossy fibers so that they form recurrent synapses onto the dentate gyrus granule cells. The distribution of zinc in the brain was altered under certain pathological conditions including epilepsy. It is 
abundant in areas prone to seizures. Aberrantly sprouted mossy fibers release zinc and this contributes to the ultimate collapse of GABA-mediated inhibitory drive in the dentate gyrus leads to chronic excitability and the spread of seizure activity (37).

Moreover, studies examining the effect of zinc on neurotoxicity have shown that micromolar concentrations of zinc protect cortical neurons from the toxic effects of excessive glutamate exposure (38). However, several lines of evidence support the idea that upon excessive synaptic zinc release, its accumulation in postsynaptic neurons contributes to the selective neuronal loss caused by generation of toxic free radicals and then cause necrotic neuronal degeneration (39). Excitotoxic brain lesions such as epilepsy lead to increasing destruction of neurons hours after the insult. This deadly cascade of events involves detrimental actions by free radicals and the activation of proapoptotic transcription factors, which finally result in neuronal destruction. The $\mathrm{Zn}^{2+}$ neurotoxicity was not attenuated by antiapoptotic agents, inhibitors of protein synthesis, caspase or glutamate receptor, or nitric oxide synthase (40).

\section{Selenium}

Selenium $\left(\mathrm{Se}^{2+}\right)$ is known to reduce lipid peroxides. The best known biological activity of $\mathrm{Se}^{2+}$ is in the seleno-enzyme GSH-Px. GSH-Px (in the form of selenocystine) with catalase and SOD is part of the cellular antioxidant defense system against free radical peroxides $(41,42)$. Cellular Se-GPX is ubiquitous in prokaryotes as well as eukaryotes (41).

Pathophysiologic mechanisms yielding epileptogenetic effect of selenium: Selenium depletion in the brain amongst patients with epilepsy may constitute an important triggering factor for the origin of intractable seizures and subsequent neuronal damage (43). Savaskan et al. (16) provided evidence that $\mathrm{Se}^{2+}$ deficiency in vivo results in a massive increase in susceptibility to kainate-induced seizures and cell loss. Primates and other animals made $\mathrm{Se}^{2+}$-deficient by dietary restriction develop alopecia, weight loss, epilepsy, and degeneration of the liver, pancreas, and kidney. Patients with systemic $\mathrm{Se}^{2+}$ deficiency develop liver disease, depigmented hair, osteoarthropathy, neuroimpairments including progressive neuronal degeneration, severe mental retardation, and intractable epilepsy $(44,45)$.

Many studies provided evidences for the role of $\mathrm{Se}^{2+}$ in neuronal susceptibility to excitotoxic lesions. In neuronal cell culture, addition of $\mathrm{Se}^{2+}$ in the form of selenite within a physiological range protects against exctiotoxic insults and even attenuates primary damage. The neuroprotective effect is not mediated via a direct antioxidant effect of selenite but requires de novo protein synthesis. Gel shift analysis demonstrates that the effect is connected to the inhibition of glutamateinduced NF-Kappa B and AP-I activation (16).

\section{Copper}

Copper $\left(\mathrm{Cu}^{2+}\right)$ is involved in number of enzymes with catalase and oxidase-type reactions. Some studies reported relationship between the serum levels of $\mathrm{Cu}^{2+}$ and $\mathrm{Zn}^{2+}$ and $\mathrm{CuZn}$-SOD activity and the serum concentration of $\mathrm{Se}^{2+}$ and GSH-Px activity in the group of healthy subjects (46). Crl (a copper-binding protein) appears to have two antioxidant properties: firstly, it binds $\mathrm{Cu}^{2+}$ and therefore prevents this transition metal from catalyzing hydroperoxide decomposition to radicals. Secondly, $\mathrm{Crl}$ oxidizes ferrous iron to ferric and concomitantly converts $\mathrm{O}_{2}$ to $\mathrm{H}_{2} \mathrm{O}$, thereby inhibiting iron-dependent lipid peroxidation (47). A moderate linear correlation was estimated between serum values of $\mathrm{Cu}^{2+}$ and $\mathrm{Crl}$ (46).

Pathophysiologic mechanisms yielding epileptogenetic effect of copper: Tsaryuk et al. (48) demonstrated that the copper-rutin complex completely eliminated epileptiform potentials induced by a combination of chlorpromazine and microwave radiation, $1-$ 2-min post-injection and suppressed convulsive activity provoked by application of penicillin to the sensorimotor cortex. On the contrary, $\mathrm{Cu}^{2+}$ and $\mathrm{Zn}^{2+}$ are known to produce seizures in animals at low dosages, which is possibly attributable to the inhibition of $\mathrm{Na}^{+}-\mathrm{K}^{+}$ATPase activity (10).

\section{Relation of lipid peroxidation and antioxidant system to neuronal excitability and excitotoxicity}

Many studies suggest that membrane lipid peroxidation may be causally involved in some forms of epilepsies, and the decrease in free radical scavenging enzyme activity is believed to cause the increased risk of seizure recurrence $(49-51)$ and idiosyncratic drug reaction encountered in the management of epilepsy $(52-54)$. It has been suggested that, an increase in free radicals may cause neuronal degeneration through membrane lipid peroxidation and a decrease in GSH-Px level (21, 55). GSH-Px deficiency is suggested to be a cause of childhood seizures (56). In an experimental study, any increase in lipid peroxide levels in the epileptic focus was found to be prevented by antioxidant treatment in epileptic rats, thereby resulting in a decreased number of epileptic discharges $(57,58)$. GSH-Px deficiency has been known as a cause of chronic granulomatous disease (59) and idiosyncratic drug reactions (60), particularly acute pancreatitis and increased lipid peroxides after therapy with valproic acid. 
Weber et al. (56), described 4 children with intractable seizures, repeated infections, and intolerance to anticonvulsants with evidence of glutathione peroxidase deficiency. Two had low intracellular enzyme activity but normal blood selenium and high plasma GSH-Px concentrations. The other two had low intracellular GSH-Px activity with low circulating GSH-Px activity and selenium concentrations. The clinical state of the children improved after discontinuation of anticonvulsant medication and selenium substitution. The first two children had primary deficiency of the intracellular enzymes, whereas the other two may have a disturbance of selenium resorption or transport.

Effect of AEDs on trace elements, membrane lipid peroxidation, and antioxidant system

Zinc

Many studies attributed altered homeostasis of trace elements in epileptic patients to epilepsy per se and/or the effect of anticonvulsant drugs therapy or due to other reasons $(10,27,60-66)$. However, conflicting results were reported by different studies. Zinc levels were reported to be normal or decreased in untreated and treated epileptics $(10,19,20,24-26,50,54,66-70)$. Kuzuya et al. (19) reported lower levels of zinc in patients who were treated with mono-AEDs (carbamazepine (CBZ), phenobarbital (PB), phenytoin (PHT), and valproate (VPA)) when compared to healthy volunteers. No dose-related changes, but the difference from controls remained within the normal range, indicating that there is no need to adjust serum concentrations in order to treat diseases related to them. Yuen et al. (71) reported normal levels of zinc in white blood cells of epileptic patients on VPA or CBZ. They suggested that AEDs might affect the intracellular zinc level concentrations. Steidl et al. (72) reported significant lowering of serum $\mathrm{Zn}^{2+}$ in patients treated with AEDs for $\geq 5$ years. They suggested that various AEDs and their combination have different effects on the degree of lowering of $\mathrm{Zn}^{2+}$. Lerman-Sagie et al. (18) in their study of evaluating the effect of VPA on $\mathrm{Zn}^{2+}$ metabolism in 15 children with absence seizures found that the erythrocyte $\mathrm{Zn}^{2+}$ content was significantly lower than that found in controls. However, the plasma and urine values of $\mathrm{Zn}^{2+}$ and $\mathrm{Cu}^{2+}$ were within the normal limits. Smith et al. (73) reported significant alteration of serum $\mathrm{Zn}^{2+}$ with $\mathrm{CBZ}$ monotherapy in epileptics.

Hair analysis has been used to evaluate the trace element status in the body (74-76). Hair levels of $\mathrm{Zn}^{2+}$ were found to be decreased in patients on AEDs compared to those in controls $(77,78,30)$. In the prospective study done by Altunbasak et al. (78), the serum and hair levels of $\mathrm{Zn}^{2+}$ were found to be higher in untreated epileptic patients than those treated with VPA and controls and returned to normal level after VPA treatment. The authors concluded that there is no $\mathrm{Zn}^{2+}$ deficiency and replacement with $\mathrm{Zn}^{2+}$ therapy may be considered unnecessary. The authors believed that hair is a reliable specimen for retrospective search of trace elements status of the body. Unlike blood, serum, and urine, the hair, in addition to being less traumatic to the patient, provides historical information on concentrations of trace elements in the body as well as nutritional condition over a long period of time $(74,79,80)$. Furthermore, trace elements are more concentrated in the hair than in the body fluids. Hair analysis provides information about intracellular accumulation of trace elements. Lastly, serum levels of trace elements in epileptic patients are unstable and may show variability during the day (81).

The real mechanism (s) of the possible effect of AEDs on $\mathrm{Zn}^{2+}$ concentrations is not completely understood, although some authors (61) have suggested that AEDs could decrease $\mathrm{Zn}^{2+}$ (with a concomitant $\mathrm{Cu}^{2+}$ increase) concentrations in epileptic patients, modifying the neurotransmitter regulation. VPA can bind zinc, thus protecting glutamic acid decarboxylase from the inhibitory effect of zinc, which results in an increased level of GABA (82).

In contrast, some studies reported slightly increased $\mathrm{Zn}^{2+}$ levels in epileptic patients $(29,54,83)$. In the studies of Kürekçi et al. (50) and Hamed et al. (83), the higher levels of zinc in treated groups of patients remained within the normal range. In the study of Kürekçi et al. (50), although weak, the correlation between the serum VPA level an plasma $\mathrm{Zn}^{2+}$ was satisfactory significant $(P<0.05, \mathrm{r}=0.554)$, which might be explained mainly by the normal physiological variation in serum zinc concentrations (circadian variation) and is unlikely related to the anticonvulsant drugs or epilepsy. It was known that plasma $\mathrm{Zn}^{2+}$ level is higher than the mean between 10:00-20:00 $(68,84)$. In the study of Kürekçi et al. (50) and Hamed et al. (83), the $\mathrm{Zn}^{2+}$ levels were measured after an overnight fast before the next morning VPA dose was taken. Other studies attributed the increased serum $\mathrm{Zn}^{2+}$ levels to measuring such levels at least $2 \mathrm{~h}$ later than VPA intake, that is, at the peak of VPA concentration (85).

In general, as previously discussed, the conflicting results of different studies of different trace elements can be mainly explained by the differences in the Materials and Methods, most studies have not been prospective, the patients receiving different AEDs were classified in the same group, and the information about the patients included was not satisfactory in most of the 
studies. In addition, the duration of drug treatment and the prescribed dose are important variables. Age of the patients whether children or adults is not a strong variable as it is believed that the plasma levels of these trace elements $\left(\mathrm{Cu}^{2+}, \mathrm{Zn}^{2+}, \mathrm{Se}^{2+}, \mathrm{Mg}^{2+}\right)$ and antioxidant enzymes (GSH-Px and SOD) do not change after the age of 3 years (86). Further prospective and experimental studies are necessary for confirmation $(7,23,87)$.

\section{Selenium}

Selenium levels were reported to be normal, decreased, or increased among epileptics. Pippenger et al. $(60,65)$, Kuzuya et al. (19), Kürekçi et al. (50), Liu et al. (70), and Verrotti et al. (20) found normal values of $\mathrm{Se}^{2+}$ in epileptic patients (treated and untreated). Hurd et al. (88) reported reduced plasma $\mathrm{Se}^{2+}$ level in patients and animals treated with VPA. Hepatic levels of $\mathrm{Se}^{2+}$ were also reduced in rats (54). It has been believed that deficiency of trace elements (e.g., $\mathrm{Se}^{2+}$ and $\mathrm{Cu}^{2+}$ ) is associated with the increased risk and idiosyncratic drug reaction encountered in the management of epilepsy. VPA has also been associated with pancreatitis, renal tubular abnormalities, and hepatotoxicity $(89,90)$. VPA may cause hepatotoxicity like that in Reye's syndrome (RS) $(52,53)$, which occur primarily in prepubertal children. Children who died of RS and mice treated with 4-pentenoic acid (a fatty acid that causes RS-like syndrome) had altered selenium and copper levels in plasma and liver $(91,92)$. In contrast, Hamed et al. (83) reported significantly increased levels of serum $\mathrm{Se}^{2+}$ in a group of patients treated with VPA in comparison to healthy controls and a CBZ-treated group of patients $(P<0.01)$. The authors in this study attributed the higher levels of $\mathrm{Se}^{2+}$ in the VPA-treated group of patients to the associated significant increase in GSH-Px levels that were also reported in the same group.

\section{Copper}

The plasma $\mathrm{Cu}^{2+}$ levels in epileptic patients contain conflicting information $(10,25,54,67-69)$. Smith and Bone (7), Pippenger et al. (60, 65), Kürekçi et al. (50), Sozuer et al. (66), Liu et al. (70,93), Shah et al. (94), and Verrotti et al. (20) reported normal serum $\mathrm{Cu}^{2+}$ levels in different groups of epileptics included in their study (untreated and treated). In contrast, Hamed et al. (83) reported significant higher levels of mean serum copper in untreated epileptics in comparison to controls $(P<0.05)$ that may be attributed to the inverse relationship between $\mathrm{Zn}^{2+}$ and $\mathrm{Cu}^{2+}$ concentrations (61). Fichsel et al. (95) found low levels of plasma copper and ceruloplasmin in children taking VPA. Tange et al. (77) reported low hair level of $\mathrm{Cu}^{2+}$ in epileptic patients on AEDs compared to that in the normal control group. The authors suggested that AEDs had more effect on hair $\mathrm{Zn}^{2+}$ than on $\mathrm{Cu}^{2+}$ and the increase in the hair $\mathrm{Zn}^{2+}$ and $\mathrm{Cu}^{2+}$, and the $\mathrm{Zn}^{2+}: \mathrm{Cu}^{2+}$ ratio seems to show the efficiency of the drug. Kaji et al. (29) reported low serum $\mathrm{Cu}^{2+}$ levels, relative to normal controls, in epileptic patients treated with VPA monotherapy or VPA in addition to other AEDs, while patients treated with other AEDs alone had unaltered $\mathrm{Cu}^{2+}$ levels. Hamed et al. (83) reported significantly lower levels of mean serum $\mathrm{Cu}^{2+}$ in treated epileptics (particularly those on CBZ monotherapy) in comparison to controls and the untreated group of patients $(P<0.05$ and $P<0.001$, respectively). None of the patients reported side effects attributed to $\mathrm{Cu}^{2+}$ deficiency.

It has been found that side effects of valproate therapy, including gastrointestinal tract (GIT) disturbance, alopecia, hyperammonemia, stupor lethargy, tremor, and anorexia $(89,96,97)$, may also follow trace metal deficiencies, particularly deficiencies in $\mathrm{Zn}^{2+}$, $\mathrm{Cu}^{2+}$, and $\mathrm{Se}^{2+}(12,79,98)$. Alopecia, achromotrichia, and changes in hair consistency are seen with both VPA treatment and $\mathrm{Cu}^{2+}$ deficiency $(62,89,99,100)$. Both $\mathrm{Zn}^{2+}$ deficiency and high-dose VPA (Package insert) produce decreased growth, decreased food consumption, and testicular and atrophy of the thymus gland in animals (101).

In contrast, increased plasma levels of $\mathrm{Cu}^{2+}$ was reported by some studies in children taking PHT therapy (67, 95, 102). Kuzuya et al. (19) reported significant increased levels of $\mathrm{Cu}^{2+}$ in patients who were treated with mono-AEDs (CBZ, PB, PHT, and VPA) when compared to healthy volunteers. No dose-related changes, and the difference from the controls remained within the normal range. Sozuer et al. (66) reported that combination therapy and CBZ increased copper level but not with VPA. Motta et al. (103) reported elevated levels of serum copper and $\mathrm{Crl}$ in adult patients on chronic AED treatment. They suggested that the AEDs may influence the serum $\mathrm{Cu}^{2+}$ and $\mathrm{Crl}$ concentrations by hepatic enzymes induction. The clinical picture of epilepsy and treatment duration does not influence serum $\mathrm{Cu}^{2+}$ and $\mathrm{Crl}$ concentrations.

\section{Lipid peroxidation and antioxidant enzymes: relation to $A E D s$}

Modification in GSH-Px and/or $\mathrm{Cu} / \mathrm{Zn}$-SOD (which are important antioxidants for detoxification of xenobiotics) may be involved in the oxidative injury of AEDs; in fact, inadequate supply of down stream scavengers of hydrogen peroxide might facilitate the transformation of hydrogen peroxide to hydroxyl radicals $(51,104)$. Maertens and associates (51) reported that long-term use of AEDs may result in an increased 
production of free radicals and elevated oxidative damage in neuronal cells. Many conventional AEDs are metabolized to generate reactive metabolites with capability of covalent binding to macromolecules. Therefore, the AEDs may not only suppress the epileptic spikes but also elicits systemic toxicity through covalent binding of their metabolic intermediates to proteins or other vital biomolecules (105).

Although decreased or normal levels of GSH and increased levels of lipid peroxidation were usually noted in many studies, the results have been rather varied. Maertens et al. (51), Liu et al. (93), Niketic et al. (22), Yüksel et al. (23), Sudha et al. (106), MartinezBallesteros et al. (107), and Hamed et al. (83) reported significant increased levels of malondialdehyde (MDA) (an index of extracellular lipid peroxidation) in untreated and treated patients in comparison to controls. Also significant increased levels in treated groups (CBZ, VPA, and polytherapy) with higher levels among the VPA-treated group. The higher levels of MDA observed among the VPA-treated group may be due to VPA metabolism generating an increased body burden of free radicals, which is responsible for serious side effects $(23,108)$. Pippenger et al. $(60,65)$ reported that GSH-Px and SOD activities in erythrocytes of children with epilepsy receiving VPA were significantly reduced. Graf et al. (108) have demonstrated that GSH-Px can be depressed in VPA-treated patients with clinically defined toxicity of the drug. On the contrary, those patients with good clinical tolerance of VPA showed normal GSH-Px activity. They considered that GSH-Px deficiency is a mediator of risk for toxicity in diverse applications of VPA. In the prospective study done by Yüksel et al. (23), in patients receiving VPA, the level of GSH-Px and SOD was markedly lowered after treatment and normal before treatment, while the level of lipid peroxidation was mildly increased before treatment and markedly increased after treatment. No significant differences of these parameters were found in epileptic children on CBZ therapy compared with the control group and the results before treatment, except that lipid peroxidation level was slightly higher in epileptic patients before treatment.

It has been known that the metabolism of VPA generates an increased body burden of free radicals (109, 110 ), and failure to remove this highly reactive species before they can inflict damage on various cellular constituents may be expressed by an increased susceptibility to the drug. The potential teratogenecity of changes in the serum trace elements and the fetal abnormalities due to VPA are similar, and the side effects encountered with chronic VPA use are also evident in disturbance of trace metal homeostasis. These deficits may be inherent or secondary to the nutritional or systemic condition (108). During VPA therapy, a decrease in GSH-Px activity has been reported due to a breakdown in the antioxidant system as well as secondary to total body depletion of $\mathrm{Se}^{2+}, \mathrm{Cu}^{2+}$, and $\mathrm{Zn}^{2+}$ (cofactors for GSH-Px activity). VPA enhances the clearance of $\mathrm{Se}^{2+}, \mathrm{Cu}^{2+}$, and $\mathrm{Zn}^{2+}$, thereby decreasing the synthesis of free radical scavenging enzymes (50). Indeed, young children have been shown to be at a higher risk to develop undesired effects upon treatment with VPA. Graf et al. (108) reported that while the level of GSH-Px in children showing good clinical tolerance to VPA treatment was close to normal, the level in children with serious side effects was decreased. They have demonstrated that GSH-Px can be depressed in VPA-treated patients with clinically defined toxicity of the drug: in particular these patients showed protracted emesis and behavioral changes and/or VPAassociated thrombocytopenia, pancreatitis, and elevated aspartate transaminase (AST). On the contrary, those patients with good clinical tolerance of VPA showed normal GSH-Px activity. The daily doses should be taken into account because high doses of VPA could modify GSH-PX; in fact, Cotariu et al. (111) reported that GSH levels in rat liver was not affected by non-toxic doses of VPA but were decreased by toxic doses. VPA and its unsaturated metabolite 4-en-VPA generated by the microsomal cytochrome P450-dependent mixed function oxidase system $(109,112)$ undergo further metabolic activation to electrophilic intermediates that bind covalently to liver macromolecules, resulting in hepatotoxicity $(110,113)$. This type of toxicity already reported for a number of xenobiotics may also involve reduced GSH depletion (114). Yüksel et al. (23) believed that VPA affects the antioxidant system, but did not agree with the comment that a decreased level of GSH-Px is an indicator of the risk of toxicity in some clinical applications. Hamed et al. (83) reported decreased level of GSH-Px in an untreated group of epileptics and increase in their levels in treated patients but they did not reach the level of significance in comparison to controls. However, patients treated with VPA and combined therapy showed significantly increased levels of GSH-Px $(P<0.001$ and $P<0.01$, respectively) in comparison to controls and CBZ group. In contrast, Kürekçi et al. (50), reported significantly higher plasma GSH-Px levels in the VPA group than in controls (in well-controlled group under treatment). How VPA increases the level of GSH-Px in plasma is unknown, but it could be attributed to induction of hepatic synthesis of GSH-Px and transport to blood (50).

Liu et al. (93) reported significantly increased levels of MDA and serum CuZn-SOD levels but the 
glutathione level was significantly decreased in all epileptic patients with PHT monotherapy compared with those of the controls. However, there was no significant difference of these parameters in the CBZ-treated patients except for a mild elevation of the activity of serum CuZn-SOD. They concluded that CBZ compared to PHT produce less disturbance in trace element metabolism, antioxidants, and lipid peroxidation in the serum of epileptic patients. The results of Liu et al. $(70,93)$ supported the notion that teratogenicity of PHT may be associated with or caused by disturbance of free radical scavenger systems, which are critical for efficient disposal of the reactive PHT metabolites $(50,51,70$, 105). PHT is metabolized by aren oxide, an electrophilic reactive intermediate, which is highly associated with increased lipid peroxidation and teratogenicity (115). In contrast, the metabolic intermediates of CBZ (e.g., the 10,11-epoxide and trans-diphenyrodiol derivative) were found to be stable, and the teratogenicity has rarely been reported in patients with CBZ monotherapy (116). An exacerbation of seizure through the release of neurotransmitters was observed in acute intoxication of patients with PHT $(50,117)$.

Furthermore, studies carried out on patients receiving $\mathrm{CBZ}$, the antioxidant enzyme activities and lipid peroxidation levels were usually similar to the levels of epileptic patients receiving no AEDs and the control group $(50,93)$ except the study of Liu et al. (93) who found mild elevation of serum SOD activity and Niketic et al. (22) who found that decrease SOD and GSH-Px. Yüksel et al. (23) reported that in epileptic patients that received CBZ, the level of GSH-Px was found to be normal while the level of serum lipid peroxidation was found to be increased in patients receiving CBZ. They concluded that antioxidant systems in epileptic patients on CBZ therapy are better regulated in comparison with epileptic children on VPA therapy. CBZ may be a better anticonvulsant for the control of free radical-related seizures (post-traumatic epilepsy) and for clinical management and treatment of female epileptic patients during pregnancy (93).

Fichsel et al. (95) and Hurd et al. (54) reported low levels of $\mathrm{Crl}$ in patients taking VPA, in contrast to the increased level among those receiving PHT $(67,95)$. Tutor-Crespo et al. (118) reported increased $\mathrm{Crl}$ and attributed this to a drug-induced cholestasis. Hamed et al. (83) reported significant decrease in the serum Crl in patients treated with CBZ and VPA in comparison to controls and untreated group.

Hyperuricemia was reported in all groups of epileptics (untreated and treated) $(P<0.001)(83)$. Hyperuricaemia observed in VPA therapy may be related to alteration of the renal excretion of the drug (119) or cellular protective mechanism against peroxidative damage. Uric acid is known to be an effective antioxidant that contributes to the effective mechanisms against oxygen radicals. The increased uric acid may be a compensatory mechanism trying to counteract oxidative stress encountered in epilepsy (120).

\section{Effect of epilepsy and antiepileptic drugs on body electrolytes}

Many previous studies suggested that routine laboratory estimation of serum sodium $\left(\mathrm{Na}^{+}\right)$, potassium $\left(\mathrm{K}^{+}\right)$, magnesium $\left(\mathrm{Mg}^{2+}\right)$, and calcium $\left(\mathrm{Ca}^{2+}\right)$ are essential for the rational understanding and management of epileptic patients. Several studies suggested that the body electrolytes play a vital role for seizure conditions to prevail $(30,121)$.

\section{Magnesium}

Serum levels of $\mathrm{Mg}^{2+}$ were found to be lowered in epileptic patients (94). Papierkowski et al. (122) reported lowered serum $\mathrm{Mg}^{2+}$ concentrations in children with febrile convulsions. A variety of pathological conditions are associated with low serum $\mathrm{Mg}^{2+}$ levels in humans. Hypocalcemia and hypokalemia frequently accompany magnesium deficiency in humans (121, 123). $\mathrm{Mg}^{2+}$ is an essential element with a role in neuronal excitability. It inhibits the facilitating effect of calcium $\left(\mathrm{Ca}^{2+}\right)$ on synaptic transmission, $\mathrm{Mg}^{2+}$ alters $\mathrm{Ca}^{2+}$ mobilization and may stabilize excitable membranes and also exerts a voltage-dependent blockage of the NMDAreceptor channel (124). It has been shown previously that low $\mathrm{Mg}^{2+}$ level-induced epileptiform activity in rat entorhinal cortex slices changes with time from a pattern of serial seizure-like events (SLEs) to a state of continuously recurring epileptiform activity. Low magnesium levels are observed in patients given anticonvulsant drugs designed for the clinical problem of pharmacoresistant epilepsy (76). In addition, efficacy of magnesium sulfate in the prevention and control of eclamptic convulsions has been validated in randomized controlled trials performed worldwide (125).

Steidl et al. (72) stated that various AEDs result in deficiency of red blood cells (RBCs) $\mathrm{Mg}^{2+}$ and serum $\mathrm{Zn}^{2+}$, and therapy of magnesium lactate produces significantly higher $\mathrm{RBC} \mathrm{Mg}^{2+}$ and serum $\mathrm{Zn}^{2+}$ with improved clinical EEG and biochemical findings (72). Iihan et al. (30) reported reduced serum level of $\mathrm{Mg}^{2+}$ in epileptic patients whether treated or not and also regardless to the type of AEDs utilized. Shah et al. (94) reported a significant decrease in serum $\mathrm{Mg}^{2+}$ levels in all seizure groups in comparison to controls, and they attributed this decrease to be responsible for hyperexcitability 
encountered for uncontrolled seizures on AEDs. However, many studies reported unchanged levels of $\mathrm{Mg}^{2+}$ in patients receiving AEDs $(7,54,72)$. In contrast, Hamed et al. (83) reported normal levels of serum $\mathrm{Mg}^{2+}$ among all groups of epileptics (treated or untreated) and irrespective to the degree of control on AEDs.

\section{Calcium}

It is well documented that alterations in the levels of serum $\mathrm{Ca}^{2+}$ are responsible for initiation of convulsions $(126-128)$. Neonatal hypocalcaemia and hypomagnesaemia have also been reported to be the cause of convulsions $(129,130)$. Serum $\mathrm{Ca}^{2+}$ levels were reported to be unaltered in generalized and unspecified seizures (94). Rutter et al. (131) reported normal serum levels in children with febrile convulsion. Hamed et al. (83) reported no difference in the levels of $\mathrm{Ca}^{2+}$ among the untreated group of patients and the normal healthy group, but reported a significant increase in the levels of serum $\mathrm{Ca}^{2+}$ in the CBZ- and VPA-treated groups of patients in comparison to controls $(P<0.05)$ and untreated group of patients $(P<0.001)$. The authors concluded that the increased serum $\mathrm{Ca}^{2+}$ levels among the treated group of patients could be a marker for better seizure control by AEDs. Shah et al. (94) reported a rise in $\mathrm{Ca}^{2+} / \mathrm{Mg}^{2+}$ ratios compared to control mean value, with unaltered $\mathrm{Ca}^{2+}$ serum levels and significantly lowering in $\mathrm{Mg}^{2+}$ levels, and they concluded that the $\mathrm{Ca}^{2+} / \mathrm{Mg}^{2+}$ ratio is a new concept and may help to judge enhancement of neuronal excitability. The elevated $\mathrm{Ca}^{2+} / \mathrm{Mg}^{2+}$ ratio was found to be closely associated with initiation and continuation of seizures. Leaver et al. (132) suggested that decline in both $\mathrm{Ca}^{2+}$ and $\mathrm{Mg}^{2+}$ concentrations results in frequent seizures.

\section{Potassium}

The deficiency in $\mathrm{K}^{+}$, is generally correlated to hypomagnesaemia and hypocalcaemia and other disturbance electrolyte homeostasis. Natelson et al. (133) and Shah et al. (93) reported reduced $\mathrm{K}^{+}$levels in untreated group of epileptics but normal levels in the treated group. The authors concluded that hypokalemia that is observed in untreated epileptics may be expressed as an increase in the ratio of intracellular to extracellular $\mathrm{K}^{+}$ concentrations, which may result into serious neurological symptoms. Hamed et al. (83) reported significant reduction in $\mathrm{K}^{+}$levels in untreated epileptics (interictal) in comparison to controls $(P<0.01)$ and treated patients $(P<0.001)$. While no difference was observed in serum $\mathrm{K}^{+}$levels in treated group (CBZ, VPA, and polytherapy) in comparison to controls and to each other.

\section{Sodium}

In general, no abnormality was noticed in serum $\mathrm{Na}^{+}$ in epileptic patients during and after seizure activity $(94,133)$. The observed hyponatraemia leading to grand mal seizures in some cases of epileptic children treated with $\mathrm{CBZ}$ was associated with water intoxication, which is a rare side effect of CBZ (134). Shah et al. (94) reported a rise in $\mathrm{Na}^{+} / \mathrm{K}^{+}$ratio as compared to control mean value, with unaltered $\mathrm{Na}^{+}$level and hypokalemia in patients was suggested to increase the recurrence of seizures (94). Natelson et al. (133) reported unaffected $\mathrm{Na}^{+}$and low $\mathrm{K}^{+}$levels during seizures. Biochonski (135) reported hypernatremia and hypokalemia in epileptic children. White et al. (136) reported elevation of $\mathrm{K}^{+}$ levels during periods of intense seizure activity.

\section{References}

1 American Medical Association. The American Medical Association's/Encyclopedia of medicine. Charles B, editor. Clayman: Random House; 1989. p. 396, p. 605, p. 752.

2 Takeda A. Zinc homeostasis and functions of zinc in the brain. Biometals. 2001;14:341-351.

3 Donaldson J, Cloutier T, Minnich JL, Barbeau A. Trace metals and biogenic amines in rat brain. Adv Neurol. 1974;5:245-252.

4 Donaldson J. Seizures in rats associated with divalent cation inhibition of $\mathrm{Na}^{+}-\mathrm{K}^{+}$-ATPase. Can J Biochem. 1971;49:12171224.

5 Wallwork JC. Zinc and the central nervous system. Prog Food Nutr Sci. 1987;11:203-247.

6 Itoh M, Ebadi M. The selective inhibition of hippocampal glutamic acid decarboxylase in zinc-induced epileptic seizures. Neurochem Res. 1982;7:1287-1288.

7 Smith WG, Bone I. Copper, zinc and magnesium plasma levels in epilepsy. J Neurol Neurosurg Psychiatry. 1982;45:1072.

8 Westbrook GL, Mayer ML. Micromolar concentrations of $\mathrm{Zn}$ antagonize NMDA and GABA response of hippocampal neurons. Nature. 1987;328:640-643.

9 Frederickson CJ, Moncrieff DW. Zinc-containing neurons. Biol Signals. 1994;3:127-139.

10 Barbeau A, Donaldson J. Zin, taurine and epilepsy. Arch Neurol. 1974;30:52-58.

11 Hunt DM. Copper and neurological function. Chiba Found Symp. 1980;79:247-266.

12 McCord EM, Weswig PH. Some selenium responses in the rat not related to vitamin E. J Nutr. 1969;98:383-389.

13 Rotruck JT, Pope AI, Ganther HE, Swanson AB, Hafeman DG, Hoekstra WG. Selenium: biochemical role as a component of glutathione peroxidase. Science. 1973;179:588-590.

14 Prasad AS. Clinical, biochemical, and pharmacological role of zinc. Ann Rev Pharmacol Toxicol. 1979;20:393-426.

15 Pfeiffer CC, Bravemann ER. Zinc, the brain and behavior. Biol Psychiatry. 1982;17:513-532.

16 Savaskan NE, Brauer AU, Kuhbacher M, Eyupoglu IY, Kyriakopoulos A, Ninnemann O, et al. Selenium deficiency increases susceptibility to glutamate-induced excitotoxicity. FASEB J. 2003;17:112-114.

17 Hirate M, Takeda A, Tamano H, Enomoto S, Oku N. Distribution of trace elements in the brain of EL (epilepsy) mice. 
Epilepsy Res. 2002;51:109-116.

18 Lerman-Sagie T, Statter M, Szabo G, Lerman P. Effect of valproic acid therapy on zinc metabolism in children with primary epilepsy. Clin Neuropharmacol. 1987;10:80-86.

19 Kuzuya T, Hasegawa T, Shimizu K, Nebeshima T. Effect of antiepileptic drugs on serum zinc, copper concentrations in epileptic patients. Int J Clin Pharmacol Ther Toxicol. 1993; 31:61-65.

20 Verrotti A, Basciani F, Trotta D, Pomilio MP, Morgese G, Chiare F. Serum copper, zinc, selenium, glutathione peroxidase and superoxide dismutase levels in epileptic children before and after 1 year of sodium valproate and carbamazepine therapy. Epilepsy Res. 2002;48:71-75.

21 Abbott LC, Nejad HH, Bottje WG, Hassan AS. Glutathione levels in specific brain regions of genetically epileptic $(\mathrm{tg} / \mathrm{tg})$ mice. Brain Res Bull. 1990;52:629-631.

22 Niketic V, Ristic S, Saicic ZS, Spasic M, Buzadzic B, Stojkovic M. Activities of antioxidant enzymes and formation of the glutathione adduct of hemoglobin (Hb ASSG) in epileptic patients with long-term antiepileptic therapy. Farmaco. 1995;50: 811-813.

23 Yüksel A, Cengiz M, Seven M, Ulutin T. Erythrocyte glutathione, glutathione peroxidase, superoxide dismutase and serum lipid peroxidation in epileptic children with valproate and carbamzepine monotherapy. J Basic Clin Pharmacol. 2000; 11:73-81.

24 Palm R, Hallmans G. Zinc and copper metabolism in phenytoin therapy. Epilepsia. 1982;23:453-461.

25 Ghose K, Taylor A. Hypercupraemia induced by antiepileptic drugs. Hum Toxicol. 1983;3:519-529.

26 Werther CA, Clud H, Ohtake M, Tamura T. Effects of long-term administration of anticonvulsants on copper, zinc and ceruloplasmin levels. Drug Nutr Interact. 1986;4:269-274.

27 Davidson SLW, Ward NI. Abnormal aluminium, cobalt, manganese, stronatium and zinc concentrations in untreated epilepsy. Epilepsy Res. 1988;1:3-13.

28 Rude RK. Physiology of Magnesium metabolism and the important role of magnesium in potassium deficiency. Am J Cardiol. 1989;63:31G-34G.

29 Kaji M, Ito M, Okuno T, Momoi T, Sasaki H, Yamanaka C, et al. Serum copper and zinc levels in epileptic children with valproate. Epilepsia. 1992;33:555-557.

30 Ilhan A, Uz E, Kali S, Var A, Akyol O. Serum and hair trace element levels in patients with epilepsy and healthy subjects: does the antiepileptic therapy affect the element concentrations of hair? Eur J Neurol. 1999;6:705-709.

31 Frederickson CJ. Neurobiology of zinc-containing neurons. Int Rev Neurobiol. 1989;31:145-238.

32 Mayer ML, Vyklicky L Jr, Westbrook GL. Modulation of excitatory amino acid receptors by group IIB metal cations in cultured mouse hippocampal neurons. J Physiol (Lond). 1989; 415:329-350.

33 Huang EP. Metal ions and synaptic transmission: think zinc. Proc Natl Acad Sci USA. 1997;94:13386-13387.

34 Takeda A, Hanajima T, Ijiro H, Ishige A, Iizuka S, Okada S, et al. Release of zinc from the brain of El (epilepsy) mice during seizure induction. Brain Res. 1999;828:174-178.

35 Donaldson J, Minnich JL, Barbeau A. Quabain-induced seizures in rats: Regional and cellular localization of ouabain associated with $\mathrm{Na}^{+}-\mathrm{K}^{+}$-ATPase in brain. Can J Biochem. 1972;50:888896.

36 Ebadi M, Wilt S, Ramaley R, Swanson S, Mebus C. The role of zinc and zinc-binding proteins in regulation of glutamic acid decarboxylase in brain. In: Evangenopoulas AD, editor. Progress in clinical and biological research. Vol. 144, Part A, Chemical and biological aspects of vitamin B6 catalysis. New York: Alan R. Liss; 1984. p. 255-275.

37 Buhl EH, Otis TS, Mody I. Zinc-induced collapse of augmented inhibition by GABA in a temporal lobe epilepsy model. Science. 1996;271:369-373.

38 Koh JY, Choi DW. Zinc alters excitatory amino acid neurotoxicity on cortical neurons. J Neurosci. 1988;8:2164-2171.

39 Weiss JH, Sensi SL, Koh JY. Zn(2+): a novel ionic mediator of neuronal injury in brain disease. Trends Pharmacol Sci. 2000; 21:395-401.

40 Kim EY, Koh JY, Kim YH, Sohn S, Joe E, Gwag BJ. Zn ${ }^{2+}$ entry produces oxidative neuronal necrosis in cortical cell cultures. Eur J Neurosci. 1999;11:327-334.

41 Burk RF, Lawrence RA, Lane JM. Liver necrosis and lipid peroxidation in a rat as a result of paraquat and diquat administration: effect of selenium deficiency. J Clin Invest. 1980; 65:1024-1031.

42 Turan B, Dalay N, Afrasyap L, Delilbasi E, Sengun Z, Sayal A, et al. The effect of selenium supplementation on antioxidative enzyme activities and plasma and erythrocyte selenium levels. Acta Physiol Hung. 1993;81:87-93.

43 Ramaekers VT, Calomme M, Vanden Berghe D, Makropoulos W. Selenium deficiency triggering intractable seizures. Neuropediatrics. 1994;25:217-223.

44 Muth OH, Weswig PH, Whanger PD, Oldfield JE. Effect of feeding selenium-deficient ration to the subhuman primate. Am J Vet Res. 1971;32:1603-1605.

45 Subcommittee on Selenium, Committee on Animal Nutrition Agricultural Board, National Research Council. Selenium in nutrition. Washington: National Academy of Science; 1971. p. 4-20.

46 Magalova T, Beno I, Brtkova A, Mekinova D, Volkovova K, Staruchova $\mathrm{M}$, et al. Levels of $\mathrm{Cu}, \mathrm{Zn}$, Se and their relation to levels of cerumloplasmin and the activity of antioxidative enzymes. Bratisl Lek Listy. 1997;98:8-11.

47 Halliwell B, Gulteridge JM. The antioxidants of human extracellular fluids. Arch Biochem Biophys. 1990;250:1-8.

48 Tsaryuk VV, Potapovich AI, Kostyuk VA. Protective effect of copper-rutin complex in animals with experimental epilepsy. Bull Exp Biol Med. 2002;133:334-335.

49 Willmore LJ, Rubin J. Antiperoxidant pretreatment and ironinduced epileptiform discharges in the rat: EEG and histopathologic studies. Neurology. 1981;31:63-69.

50 Kürekçi AE, Alpay F, Tanindi S, Gökçay E, Özcan O, Akin R, et al. Plasma trace element, plasma glutathione peroxidase, and superoxide dismutase levels in epileptic children receiving AEDs therapy. Epilepsia. 1995;36:600-604.

51 Maertens P, Dyken P, Graf E, Pippenger C, Chronister R, Shah A. Free radicals, anticonvulsants and the neuronal ceroidlipofuscinoeses. Am J Med Genet. 1995;57:225-228.

52 Gerber N, Dickinson RG, Harland RC, Lynn RK, Houghton LD, Antonias JI, et al. Reye-like syndrome associated with valproic acid therapy. J Pediatr. 1979;95:142-144.

53 Young RSK, Bergman I, Gang DL, Richardson EP. Fatal Reyelike syndrome associated with valproic acid. Ann Neurol. 1980;7:389.

54 Hurd RW, Van Rinsvelt HA, Wilder BJ, Karas B, Maenhaut W, DeReu L. Selenium, zinc and copper changes in valproic acid: possible correlation to drug side effects. Neurology. 1984; 34:1393-1395.

55 Jesberger JA, Richardson JS. Oxygen free radicals and brain 
dysfunction. Int J Neurosci. 1991;57:1-7.

56 Weber GF, Maertens P, Meng X, Pippenger CE. Glutathione peroxidase deficiency and childhood seizures. Lancet. 1991; 337:1443-1444.

57 Hall ED, Braughler JM. Central nervous system trauma and stroke. Physiological and pharmacological evidence for involvement of oxygen radicals and lipid peroxidation. Free Radic Biol Med. 1989;6:303-313.

58 Liu J, Mori A. Antioxidant and free radical scavenging activities of Gastrodia elata Bl. and Uncoria rhynchophylla (Miq.) jacks. Neuropharmacology. 1992;31:1287-1298.

59 Holmes B, Park BH, Malawista SE, Quie PG, Nelson DL, Good RA. Chronic granulomatous disease in females. A deficiency of leukocytes glutathione peroxidase. N Engl J Med. 1970;283; 217-221.

60 Pippenger CE, Meng X, van Lente F. Alternative approaches to the prediction of antiepileptic idiosyncratic or drug-drug interactions. New York: Demos; 1989. p. 293-307.

61 Abdulla A, Ibse I. Utesluter normalt zinc serum zinkbrist? Lakartidningen. 1976;73:2104-2105. (text in Swedish with English abstract)

62 Evans GW. The role of copper in metabolic disorders. Adv Exp Med Biol. 1981;135:121-137.

63 Flanagan PR, Haist J, Valbery LS. Zinc absorption, intraluminal and intestinal metallothinein levls in zinc-deficient and zincreplete rodents. J Nutri. 1983;237:335-339.

64 Akram M, Sullivan C, Mack G, Buchanan N. What is the clinical significance of reduced manganese and zinc levels $\mathrm{n}$ treated epileptic patients? Med J Aust. 1989;151:113-114.

65 Pippenger CE, Meng X, Von Lente F, Rothner AD. Valproate therapy suppresses GSH.PX and SOD enzyme activity. A possible mechanism for VPA induced idiosyncratic drug toxicity. Clin Chem. 1989;35:1173.

66 Sozuer DT, Barutcu UB, Karakoc Y, Yalcin E, Onen S. The effects of antiepileptic drugs on serum zinc and copper levels in children. J Basic Clin Physiol Pharmacol. 1995;6:265-269.

67 Tutor JC, Fernandez MP, Paz JM. Serum copper concentration and hepatic enzyme induction during long therapy with anticonvulsants. Clin Chem. 1982;28:1367-1370.

68 Taylor A, Ghose K. Diurnal variation of serum copper and zinc in epileptics receiving anticonvulsants. Hum Toxicol. 1986;5: 195-200.

69 Suzuki T, Koizumi J, Moroji T, Shiraishi H, Hori T, Baba A, et al. Effects of long-term anticonvulsants on copper, zinc and magnesium in hair and serum of epileptics. Biol Psychiatry. 1992;31:571-581.

70 Liu CS, Wu HM, Kao SH, Wei YH. Phenytoin-mediated oxidative stress in seum of female epileptics: a possible pathogenesis in fetal hydantoin syndrome. Hum Exp Toxicol. 1997;31:61-65.

71 Yuen WC, Whiteoak R, Thompson RP. Zinc concentrations in leucocytes of patients receiving antiepileptic drugs. J Clin Pathol. 1988;41:553-555.

72 Steidl L, Tolde I, Svomova V. Metabolism of magnesium and zinc in patients treated with antiepileptic drugs and with magnesium lactate. Magnesium. 1987;6:284-295.

73 Smith AJ, Hoorntje SJ, Donker AJM. Zinc deficiency during captopril treatment. Nephron. 1983;34:196-197.

74 Laker M. The uses of blood and hair on determining trace element levels in man. Lancet. 1982;31:260-262.

75 Manson P, Zlotkin S. Hair analysis - a critical review. Can Med Assoc J. 1985;133:186-188.

76 Dreier JP, Zhang C-L, Heinemann U. Phenytoin, phenobarbital, and midazolam fail to stop status epilepticus-like activity induced by low magnesium in rat entorhinal slices, but can prevent its development. Acta Neurol Scand. 1998;98:154-160.

77 Tange SM. Hair zinc and copper concentrations in patients with epilepsy. Zhonghua Shen Jing Shen Ke Za Zhi. 1991;24:94-97, 124-125. (abstract in Chinese)

78 Altunbasak S, Biatmakoui F, Baytok V, Herguner O, Burgt HR, Kayrin L. Serum and hair zinc levels in epileptic children taking valproic acid. Biol Trace Elem Res. 1997;58:117-125.

79 Agget PJ, Harries JT. Current status of zinc in health and disease states. Arch Dis Child. 1979;54:909-917.

80 Harris WR. Thermodynamic binding constants of the zinchuman serum transferrin complex. Biochemistry. 1983;22:3920 3926.

81 Ulvi H, Yigiter R, Yoldas T, Dolu Y, Var A, Müngen B. Magnesium, zinc, copper contents in hair and their serum concentrations in patients with epilepsy. East J Med. 2002;7:31-35.

82 Hurd RW, Wilder BJ, Street JJ, Sciscent BL. Zinc binding by valproic acid. Neuroscience Abstr. 1981;7:813.

83 Hamed SA, Abdellah MM, El-Melegy N. Blood levels of trace elements, electrolytes, and oxidative stress/antioxidant systems in epileptic patients. J Pharmacol Sci. 2004;96:465-473.

84 Lifschitz MD, Henkin RI. Circadian variation in copper and zinc in man. J App Physiol. 1971;31:88-92.

85 Rall TW, Schleifer LS. Drugs effective in the therapy of epilepsies. Goodman and Gilman's the pharmacological basis of therapeutics, 8th ed. Singapore: Pergamon Press, 1991. p. 436462.

86 Shaw JCL. Trace elements in the fetus and young infant. Am J Dis Child. 1979;133:1260-1264.

87 Schott GD, Delves HT. Plasma zinc levels with anticonvuslant therapy. Br J Clin Pharmacol. 1978;5:279-280.

88 Hurd RW, Wilder BJ, Van Rinsvelt HA. Valproate, birth defects and zinc. Lancet. 1983;22:181.

89 Committee on Drugs (Pruitt AW, chairman). Valproic acid benefits and risks. Pediatrics. 1982;70:316-319.

90 Lenoir GR, Perignon JL, Gubler MC, Broyer M. Valproic acid: a possible cause of proximal tubule renal syndrome. J Pediatr. 1981;98:503-504.

91 Van Rinsvelt HA, Lear RD, Adams WR. Human diseases and trace elements. Investigation by proton induced $\mathrm{x}$-ray emission. Nucl Inst Method. 1977;142:171-180.

92 Ozawa Y, Inagaki Y, Yonei Y, Tsukada N, Okawa H, Kiryu Y, et al. An adult case of Reye like syndrome and acute pancreatitis associated with sodium valproate. Nippon Shokakibyo Gakkai Zasshi. 1992;89:1467-1470. (text in Japanese with English abstrct)

93 Liu C, Wu H, Kao S, Wei Y. Serum trace elements, glutathione, copper/zinc superoxide dismutase, and lipid peroxidation in epileptic patients with phenytoin or carbamazepine monotherapy. Clin Neuropharmacol. 1998;21:62-64.

94 Shah QA, Jamil AA, Gupta VP, Kabiraj MM, Shah AH. Changes in serum electrolytes in childhood epilepsy: A hospitalbased prospective. Greenwich J Sci Technol. 2001;2:18-27.

95 Fichsel H, Niewerth B, Schlehbusch H. Influence of antiepileptic drugs on copper and ceruloplasmin concentrations in epileptic children and juvenile in antiepileptic therapy. In: Oxley J, Janz D, Meinardi H, editors. Chronic toxicity of antiepileptic drugs. New York: Raven Press; 1983. p. 85-90.

96 Sherard ES, Steiman GS, Couri D. Treatment of childhood epilepsy with valproic acid: results of the first 100 patients in a six months trial. Neurology. 1980;30:31-35.

97 Wilder BJ, Bruni J. Seizure disorders: a pharmacological 
approach to treatment. New York: Raven Press; 1981. p. 83-96.

98 Solomons NW. Zink and copper in human nutrition. In: Selvey N, White PL, editors. Nutrition in the 1980's: constraints on our knowledge. New York: AL Liss; 1981. p. 97-127.

99 Jeavons P, Clark J, Harding G. Valproate and curly hair. Lancet. 1977;1:359.

100 Herranz JL, Arteaga R, Armijo JA. Change in hair color induced by valproic acid. Dev Med Child Neurol. 1981;23:386-387.

101 Millar MJ, Fischer MI, Elcoate PV, Mayson CA. The effects of dietary zinc deficiency on the reproductive system of male rats. Can J Biochem Physiol. 1958;36:557-569.

102 Brunia CHM, Buyze G. Serum copper levels and epilepsy. Epilepsia. 1972;13:621-625.

103 Motta E, Miller K, Ostrowska Z. Concentration of copper and ceruloplasmin in serum of patients treated for epilepsy. Wiad Lek. 1998;51:156-161. (text in Polish with English abstract).

104 Dakin KA, Weaver DF. Mechanism of post-traumatic seizures: a quantum pharmacological analysis of the molecular properties of an epileptogenic focus following iron-induced membrane peroxidation. Seizure. 1993;2:21-23.

105 Lindhout DH, Oppener RJ, Meinardi H. Teratogenicity of antiepileptic drug combinations with special emphasis on epoxidation (of carbamazepine). Epilepsia. 1984;25:77-83.

106 Sudha K, Rao AV, Rao A. Oxidative stress and antioxidants in epilepsy. Clin Chem Acta. 2001;303:19-24.

107 Martinez-Ballesteros C, Pita-Calandre E, Sanchez-Gonzalez Y, Rodriguez-Lopez CM, Agil A. Lipid peroxidation in adult patients treated with valproic acid. Rev Neurol. 2004;38:101106. (text in Spanish with English abstract)

108 Graf WD, Oleinik OE, Glauser TA, Maertens P, Eder DN, Pippenger CE. Altered antioxidant activities in children with a serious side adverse experience related to valproic acid therapy. Neuropediatrics. 1998;29:195-201.

109 Rettie AE, Rettenmeier AW, Howald MN, Baillie TA. Cytochrome P450 catalyzed fromation of 4-VPA, a toxic metabolite of valproic acid. Science. 1987;235:890-893.

110 Rettenmeier AW, Prickett KS, Gordon PW, Bjorge SM, Change SL, Levy RH, et al. Studies on the biotransformatin in the perfused rat liver of 2-n-propyl-4pentenoic acid, a metabolic of the antiepileptic drug valproic acid. Evidence for the formation of chemically reactive intermediates. Drug Metab Dispos. 1985;13:81-96.

111 Cotariu D, Evans S, Zaidman JL, Marcus O. Early changes in hepatic redox homeostasis following treatment with a single dose of valproic acid. Biochem Pharmacol. 1990;40:589-593.

112 Rettie AE, Boberg M, Rettenmeier AW, Ballie TA. Cytochrome $\mathrm{P} 450$-catalyzed desaturation of valproic acid in vitro. Species differences, induction effects, and mechanistic studies. J Biol Chem. 1988;263:13733-13738.

113 Porubek DJ, Grillo MP, Baillie TA. The covalent binding to protein of valproic acid and its hepatotoxic metabolite, 2-npropyl-4-pentenoic acid, in rats and in isolated rat hepatoctyes. Drug Metab Dispos. 1989;17:123-130.

114 Guengerich PF, Liebler DC. Enzymatic activation of chemicals to toxic metabolites. CRC Crit Rev Toxicol. 1985;14:259-307.

115 Roy D, Snodgrass WR. Covalent binding of phenytoin to protein and modulation of diphenylhydantoin metabolism by thiols in A/J mouse liver microsomes. J Pharmacol Exp Ther. 1990; 252:895-900.

116 Eichelbaum M, Tomson T, Tybring G, Bertilsson L. Carbamazepine metabolism in man: induction and pharmacogenetic aspects. Clin Pharmacokinet. 1985;10:80-90.

117 Vida JA. Anticonvulsants. In: Balado D, editor. Principles of medical chemistry. Baltimore: Williams and Wilkins; 1985. p. $190-191$.

118 Tutor-Crespo MJ, Hermida J, Tutor JC. Assessment of copper status in epileptic patients treated with anticonvulsant drugs by measuring specific oxidase activity of ceruloplasmin. Epilepsy Res. 2003;56:147-153.

119 Maesaka JK, Fishban S. Regulation of renal urate excretion: a critical review. Am J Kidney Dis. 1998;32:917-933.

120 Ames BN, Catheart R, Schwiers E, Hochstein P. Uric acid provides an antioxidant defense in humans against oxidant and radical-caused aging and cancer: a hypothesis. Proc Natl Acad Sci USA. 1981;78:6858-6862.

121 Rude RK. Magnesium metabolism and deficiency. Endocrinol Metab Clin North Am. 1993;22:377-395.

122 Papierkowski A, Mroczkowska JA, Pawlowska KA, Pasternak $\mathrm{K}$. Magnesium and zinc levels in blood serum and cerebrospinal fluid in children with febrile convulsions. Pol Merkuriusz Lek. 1999;6:138-140.

123 Roitg I, Jamard B, Constantin A, Cantagrel A, Mazieres B, Laroche M. Severe refractory hypocalcemia in patients with enteropathy: consider hypomagnesemia. Joint Bone Spine. 2004;71:252-253.

124 Kandel ER. Transmitter release. In: Principles of neuronal science. Kandel ER, Schwartz JH, Vessel TM, editors. New York: Elsevier; 1991. p. 194-212.

125 Lewis R, Sibai B. Recent advances in the management of preeclampsia. J Matern Fetal Med. 1997;6:6-15.

126 Musiolino R, DeDeomenico P, Marino D, Labet C, Serra S, Siluestri R, et al. Epilepsy associated with hypocalcemia: description of a family. Funct Neurol. 1992;7:215-222.

127 Nzeh DA, Erasmus RT, Aiyedun BA. Serum electrolytes and protein changes after intravenous injection of sodium and meglumine diatrizoate (Urograffin-370). Afr J Med Sci. 1994;23:35-37.

128 Kiviranta T, Tuomisto L, Airaksine EM. Osmolarity and electrolytes in cerebrospinal fluid and serum of febrile children with and without seizures. Eur J Pediatr. 1996;155:120-125.

129 Lynch BJ, Rust RS. Natural history and outcome of neonatal hypocalcemic and hypomagnesemic seizures. Pediatr Neurol. 1994;11:23-27.

130 Sheth DP. Hypocalcemic seizures in neonates. Am J Emerg Med. 1997;15:638-641.

131 Rutter N, Smales OR. Calcium, magnesium and glucose levels in blood and CSF of children with febrile convulsions. Arch Dis Child. 1976;5:141-143.

132 Leaver DD, Parkinson GB, Schneider KM. Neurological consequences of magnesium deficiency: correlations with epilepsy. Clin Exp Pharmacol Physiol. 1987;14:361-370.

133 Natelson S, Miletich DJ, Seals CF, Visintine DJ, Albrecht RF. Clinical biochemistry of epilepsy 1 . Nature of the disease and a review of chemical findings in epilepsy. Clin Chem. 1979;25: 889-897.

134 Koivikko MJ, Valikangas SL. Hyponatraemia during carbamazepine therapy in children. Neuropediatrics. 1983;14:93-96.

135 Biochonski R. Electrochemical blood properties in epileptic children. Neurol Neurochir Pol. 1976;10:249-254.

136 White HS, Chow SY, Yen-Chow YC, Woodbury DM. Effect of elevated potassium on the ion content of mouse astrocytes and neurons. Can J Physiol Pharmacol. 1992;70 Suppl:S263-S268. 